\title{
Experimental Investigation and Performance Evaluation of a Closed Loop Pulsating Heat Pipe
}

\author{
R. Naik ${ }^{1 \dagger}$, V. Varadarajan ${ }^{2}$, G. Pundarika ${ }^{3}$ and K. R. Narasimha ${ }^{4}$ \\ ${ }^{1,2}$ Department of Mechanical Engineering, BM S College of Engineering, Bangalore, 560019, India \\ ${ }^{3}$ Principal, Government Engineering College Ramanagara, India \\ ${ }^{4}$ Centre for Emerging Technologies, Jain University, Bangalore, 562112, India
}

$\dagger$ Corresponding Author Email: rudranaik35@rediffmail.com

(Received August 10, 2011; accepted February 10, 2012)

\begin{abstract}
Pulsating heat pipe (PHP) cooling is the new and emerging technique in the field of thermal management of electronics. In the present work, transient and steady state experiments are conducted on a single turn closed loop PHP. Evaporator and condenser wall temperatures are measured. Copper is used as the capillary tube material in the evaporator and condenser sections with inner diameter of $1.95 \mathrm{~mm}$ and outer diameter of $3 \mathrm{~mm}$. The total length of the closed loop pulsating heat pipe is $540 \mathrm{~mm}$. The evaporator and condenser sections are $185 \mathrm{~mm}$ and $195 \mathrm{~mm}$ respectively. The experiments are conducted both in the horizontal as well as in vertical orientations for different heat loads varying from $9 \mathrm{~W}$ to $15 \mathrm{~W}$ in steps of $2 \mathrm{~W}$. The PHP is tested with different working fluids viz., Acetone, Methanol and Ethanol for different fill ratios from $60 \%$ to $80 \%$ in steps of $10 \%$. The performance parameters such as temperature difference between evaporator and condenser, thermal resistance and the overall heat transfer coefficient are evaluated. The experimental results demonstrate that Acetone is the better working fluid among the working fluids considered in terms of lower thermal resistance and higher heat transfer coefficient. The heat transfer characteristics of PHP are found to be better at a fill ratio of $60 \%$. The single loop PHP is found to perform better with horizontal orientation for all heat loads, working fluids and fill ratios considered.
\end{abstract}

Keywords: Pulsating heat pipe, Fill ratio, Orientation, Working fluids.

NOMENCLATURE

$\begin{array}{ll}A_{s} & \text { surface Area }\left(\mathrm{m}^{2}\right) \\ A C H & \text { Acetone in Horizontal Orientation } \\ A C V & \text { Acetone in Vertical Orientation } \\ d & \text { inner diameter of PHP (m) } \\ E T H & \text { Ethanol in Horizontal Orientation } \\ E T V & \text { Ethanol in Vertical Orientation } \\ F R & \text { Fill Ratio } \\ h & \text { heat transfer coefficient }\left(\mathrm{W} / \mathrm{m}^{2} \mathrm{~K}\right) \\ k & \text { thermal conductivity (W/m K) } \\ L_{c} & \text { length of condenser section (m) } \\ L_{e} & \text { length of evaporator section (m) } \\ M T H & \text { Methanol in Horizontal Orientation } \\ M T V & \text { Methanol in Vertical Orientation } \\ P H P & \text { Pulsating Heat Pipe }\end{array}$

$\begin{array}{ll}Q & \text { heat load }(\mathrm{W}) \\ R & \text { thermal resistance }(\mathrm{K} / \mathrm{W}) \\ t & \text { time }(\mathrm{s}) \\ T_{c} & \text { condenser temperature }\left({ }^{0} \mathrm{C}\right) \\ T_{e} & \text { evaporator temperature }\left({ }^{0} \mathrm{C}\right)\end{array}$

$\mathrm{T}_{1}, \mathrm{~T}_{2}, \mathrm{~T}_{3}, \mathrm{~T}_{4}$ temperatures measured at position 1 , $2,3,4$ of thermocouple in heating section

$\mathrm{T}_{5}, \mathrm{~T}_{6} \quad$ temperatures measured at position 5, 6 of thermocouple in condenser section

$\Delta \mathrm{T}_{1}, \Delta \mathrm{T}_{2}, \quad$ change in emperatures measured at $\Delta \mathrm{T}_{3}, \Delta \mathrm{T}_{4} \quad$ position $1,2,3,4$ of thermocouple in heating section

$\Delta \mathrm{T}_{5}, \Delta \mathrm{T}_{6} \quad$ change in temperatures measured at position 5, 6 of thermocouple in condenser section 


\section{INTRODUCTION}

Thermal management is the challenge of the day in electronic product development. The amount of excess heat generated by the electronic devices and circuitry has increased enormously. All electronic components from microprocessors to high-end power converters generate heat and rejection of this heat is necessary for their optimum and reliable operation. As electronic design allows higher output in smaller packages, effective heat load dissipation becomes a critical design factor. Many of the present days electronic devices require cooling beyond the capability of conventional metallic heat sinks. One solution to remove excess heat is by utilization of heat pipes which are employed to remove the excess heat by directly attaching them to the heat source. The Oscillating or pulsating heat pipe (PHP) is another promising heat transfer device for applications like electronic cabinet cooling. These simple looking devices have intriguing thermohydrodynamic operational characteristics. A PHP is partially filled with working fluid which distributes itself naturally in the form of liquid slugs and vapor plugs inside the capillary tubes. One end of this tube bundle (evaporator section) receives heat, transferring it to the other end (condenser section) by a pulsating action of the liquid-vapor system. A PHP is essentially a non equilibrium heat transfer device driven by complex combination of various types of two-phase flow instabilities. The performance success of a PHP primarily depends on the continuous maintenance or sustenance of these non equilibrium conditions. The liquid slugs and vapor plugs are transported because of the pressure pulsations caused inside the system. The construction of the device inherently ensures that no external mechanical power source is needed for the fluid transport. The driving pressure pulsations are fully thermally driven.

Single and multiple loop PHP studies are widely reported in the literature. These studies highlight the influence of various design parameters of PHP on its performance.

The PHP was first invented by Akachi (1990). In his patent (US Patent, 4921041), he described 24 different types of loop type heat pipes. All the proposed structures consisted of one or more non- return flow check valve to ensure a proper flow direction in the tubes. The inner diameter of the tubes was reported as 2 $\mathrm{mm}$. Water and R-11 were used as the working fluids. It was claimed that working fluids which are unsuitable for conventional heat pipe can be used in PHP with better performance. The thermal resistance values reported was ranging from $0.082 \mathrm{~K} / \mathrm{W}$ to $0.233 \mathrm{~K} / \mathrm{W}$ for water and 0.077 to $0.189 \mathrm{~K} / \mathrm{W}$ for R-11 in the heat load range of 92 to $310 \mathrm{~W}$. In their study, R-11 was found to be the most suitable for PHP.

Charoensawan et al (2001) conducted experimental investigation on range of multi turn PHPs. The closed loop PHPs were made of copper tubes of internal diameters $2 \mathrm{~mm}$ and $1 \mathrm{~mm}$. water, ethanol and R-123 were used as the working fluids. The authors identified that the relative share of sensible and latent heat transfer in a PHP is influenced by the working fluid. It is evident that the type of flow (i.e. slug/annular flow), the average flow velocity and overall pressure drop in PHP depends on the working fluid. It was also found that the bubble nucleation, collapse, shapes and bubble pumping action were influenced by the working fluid. In their experiments, they observed better performance of PHP with water at vertical orientation with $2 \mathrm{~mm}$ inner diameter. With $1 \mathrm{~mm}$ diameter tubes, they obtained better result with R123 and ethanol.

Khanderkar et al (2003) presented visualization results in a PHP in order to highlight the complexities involved in the mathematical modeling of PHP. The flow visualization studies reported clearly shows the existence of slug /semi annular flow/annular flow in a PHP.

Khandekar (2008) demonstrated the existence of multi quasi- steady state in a PHP by developing an experimental test rig of a single loop PHP made of copper tubes of inner diameter $2 \mathrm{~mm}$ and outer diameter $3 \mathrm{~mm}$. The experiments were conducted for heat input of $10 \mathrm{~W}, 15 \mathrm{~W}$ and $20 \mathrm{~W}$ with ethanol as the working fluid at $60 \%$ fill ratio. A tendency of liquid hold-up was observed in the condenser section which made the evaporator zone drier and hotter. It was observed that the churn flow takes place in the evaporator and slug flow in the condenser zone. It was also noticed that continuous heat transfer takes place in the evaporator and condenser at steady state. The effect of heat load on the performance of PHP was reported in this investigation which shows that an increase in heat load increases the operating temperature resulting in better thermal performance. This study shows the results of single loop PHP with only ethanol as working fluid at a fill ratio of $60 \%$ and does not report the effect of other working fluids and fill ratios on the performance of PHP.

Cai et al (2006) studied the effect of heat load on the performance of PHP. The authors have developed copper non looped PHP of inner diameter $1.568 \mathrm{~mm}$ and $1.397 \mathrm{~mm}$. It was observed that the operating temperature increases with the increase in heat load.

Shi Liu et al (2007) developed three types of PHP configuration with varying cross sections. It was found from their experiments that the thermal resistance of a PHP decreases with the increase in heat load.

Meena et al (2008) studied the effect of inner diameter and orientation on the performance of a closed loop PHP with check valves. The authors developed two experimental setups of copper tubes of $1.77 \mathrm{~mm}$ and $2.03 \mathrm{~mm}$ inner diameters with 10 turns. They maintained equal lengths of $5 \mathrm{~cm}$ in evaporator, condenser and adiabatic sections in their setup. A fill ratio of $50 \%$ was used and the working fluid used was $\mathrm{R}$ - 123. The experiments were conducted for different orientations of $0,20,40,60,80$, and 90 degree. It was showed that the critical heat flux increases with the increase in orientation.

Yang et al (2008) has presented an experimental study on the operational limitation of closed loop PHPs which consists of a total of 40 copper tubes with $1 \mathrm{~mm}$ and 2 $\mathrm{mm}$ inner diameters with R-123 as the working fluid. The experiments were conducted in vertical bottom heat mode, horizontal heat mode and vertical top heat mode. The effect of inner diameter and heating mode on the 
thermal performance of PHP were investigated. Their result showed that the best performance exists in the vertical bottom heat mode position and does not play any role with $1 \mathrm{~mm}$ diameter. The PHPs were operated till a performance limit characterized by evaporator overheating (dry-out) occurrence. Dry out heat fluxes reported in the vertical bottom heat mode were about $1242 \mathrm{~W} / \mathrm{cm}^{2}$ (1 $\left.\mathrm{mm} \mathrm{ID}\right)$ and $430 \mathrm{~W} / \mathrm{cm}^{2}$ (2 $\mathrm{mm}$ ID) for axial heat transport and about $32 \mathrm{~W} / \mathrm{cm}^{2}$ (1 mm ID) and $24 \mathrm{~W} / \mathrm{cm}^{2}$ (2mm ID) for radial heat load.

Rama Narasimha et al (2012) conducted experimental work on single loop PHP with copper tube of $2 \mathrm{~mm}$ ID and $3 \mathrm{~mm}$ OD in the evaporator and condenser sections, glass tube of $3 \mathrm{~mm}$ ID and $4 \mathrm{~mm}$ OD as adiabatic section. Transient studies were conducted for different heat input, working fluid and evacuation levels. It was demonstrated that acetone is the most suitable working fluid for PHP operation and the performance of the PHP was found to be better at atmospheric conditions compared to evacuation conditions. Authors have also conducted Power Spectral Density analysis for the same. In this analysis, the frequency distribution of temperature variation in PHP was observed over a wider range, signifying the periodic motion in the fluid flow of the liquid slug and vapor plug. This characteristic frequency corresponded to the characteristic time for a couple of adjacent vapor plug and liquid slug passing through a specific local wall surface in a PHP. Their study is carried out only in the horizontal orientation of PHP.

Thus the literatures available on single loop PHP have reported the experimental work restricting only ethanol as a working fluid for a particular fill ratio and orientation. Not many experimental data have been reported on single loop PHP with respect to different working fluids, fill ratio and orientation. In the present work, an attempt has been made to address all these issues by thorough systematic experimental investigation on single loop PHP for different fill ratios, working fluids, heat input and orientation in order to evaluate the performance parameters such as thermal resistance and heat transfer coefficient. An attempt is also made to determine the best working fluid under various operating conditions.

\section{DesCRIPTION OF The EXPERIMENTAL SETUP AND THE EXPERIMENTAL Procedure}

Figure 1 shows the schematic diagram of the experimental setup. In this setup, copper is used as the capillary tube material in the evaporator and condenser sections with inner diameter of $1.95 \mathrm{~mm}$ and outer diameter of $3 \mathrm{~mm}$. The total length of the closed loop pulsating heat pipe is $540 \mathrm{~mm}$. The evaporator and condenser lengths are $185 \mathrm{~mm}$ and $195 \mathrm{~mm}$ respectively. In order to visualize the flow in the PHP, a glass tube is connected between evaporator and condenser sections for a length of $160 \mathrm{~mm}$. In the present investigation, borosilicate glass of inner diameter $2 \mathrm{~mm}$ and outer diameter $3 \mathrm{~mm}$ is employed. Silicon rubber tubes of $2 \mathrm{~mm}$ inner diameter and $4 \mathrm{~mm}$ outer diameter are used as connectors between glass and copper tubes. The silicon rubber tubes employed here as connectors, can withstand high temperatures up to $400{ }^{\circ} \mathrm{C}$. They are also leak proof and can expand at higher temperatures. A Tape heater of $0-50 \mathrm{~W}$ capacity with $6 \mathrm{~mm}$ width and $185 \mathrm{~mm}$ length is employed during the experiments for heating the working fluid. Six J type thermocouples are used for the temperature measurement. The operating temperature range of these $\mathrm{J}$ type thermocouples is -50 to $500{ }^{\circ} \mathrm{C}$ with a maximum error of $\pm 0.1{ }^{\circ} \mathrm{C}$. Four thermocouples are fixed in the evaporator section and two in the condenser section. The temperatures measured by four thermocouples in the evaporator section are named as $T_{1}, T_{2}, T_{3}$ and $T_{4}$ respectively. The temperatures measured by two thermocouples in the condenser section are named as $\mathrm{T}_{5}$ and $T_{6}$ respectively. The thermocouples are fixed on the walls of the copper tube. The thermocouples are calibrated using saturated steam and ice bath and found to be consistent with the standard calibration curve. Experiments are repeated in order to ensure the consistency of the thermocouples. The temperature values are recorded with a frequency of $2 \mathrm{~Hz}$ using a temperature data logger.

The glass wool is uniformly smeared throughout the entire setup so as to ensure that the experimental setup is well insulated.

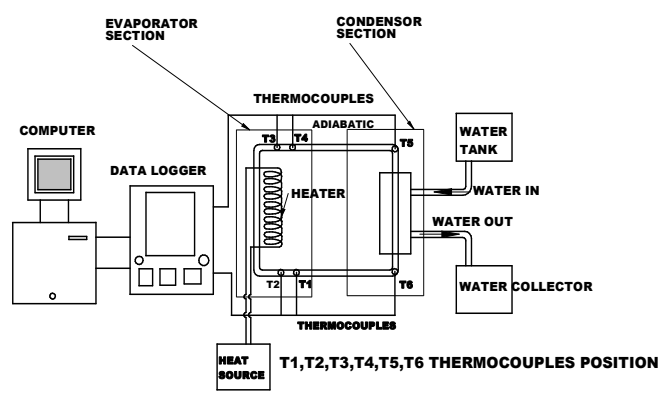

Fig. 1. Experimental Schematic of the PHP

Following procedure is adopted during the present transient and steady state experimentation:

1. Before filling the working fluid, air is blown inside the heat pipe to ensure that there is no fluid present inside the PHP.

2. PHP is filled with working fluid using a syringe for the required amount. The experiments are conducted for different fill ratios ranging from $60 \%$ to $80 \%$ in steps of $10 \%$. It is reported in the literature that PHP works as a true pulsating device when the fill ratio is ranging from $50 \%$ to $80 \%$ (Khandenkar et al 2004). Hence, in the present investigation the fill ratio is chosen in the range of $60 \%$ to $80 \%$.

3. The PHP is heated with the help of a power source and a tape heater.

4. Data logger is switched on to record the temperature readings.

5. The cooling water is allowed to flow through the PHP to the condenser section of PHP from the constant water bath at a flow rate of $2 \mathrm{ml} / \mathrm{sec}$ in such a way that the temperature rise of cooling water in the condenser is always maintained at $1^{0} \mathrm{C}$. 
6. The required wattage is set using the power supply unit and the heat load is varied from $9 \mathrm{~W}$ to $15 \mathrm{~W}$ insteps of $2 \mathrm{~W}$.

Experiments are conducted in the horizontal as well as vertical orientation of PHP with different working fluids viz., Acetone, Methanol and Ethanol.

\section{RESUlts AND DiscuSSION}

Transient and steady state experiments are conducted with different working fluids viz., acetone, ethanol and methanol. The experiments are carried out at different heat loads, fill ratio and orientation and the evaporator and condenser wall temperature readings are recorded.

\subsection{Effect of heat input on evaporator temperature}

As there is a continuous pressure pulsation during the flow in a PHP, there will be fluctuations in both the evaporator and condenser temperatures even at steady state. There are four thermocouples mounted in the evaporator section and two in the condenser section and hence the uncertainty in the evaporator temperature and condenser temperature $U_{e}$ and $U_{c}$ are evaluated respectively as (Kline et al 1953),

$\% U_{e}=\sqrt{\left(\frac{\Delta T_{1}}{T_{1}}\right)^{2}+\left(\frac{\Delta T_{2}}{T_{2}}\right)^{2}+\left(\frac{\Delta T_{3}}{T_{3}}\right)^{2}+\left(\frac{\Delta T_{4}}{T_{4}}\right)^{2}}$

$\%_{c}=\sqrt{\left(\frac{\Delta T_{5}}{T_{5}}\right)^{2}+\left(\frac{\Delta T_{6}}{T_{6}}\right)^{2}}$

The maximum uncertainty obtained in the temperature readings using equations (1) and (2) is about $5 \%$.

Figure 2 shows the variation of evaporator wall temperature with respect to time in the horizontal orientation of operation of PHP for Acetone at a fill ratio of $80 \%$.

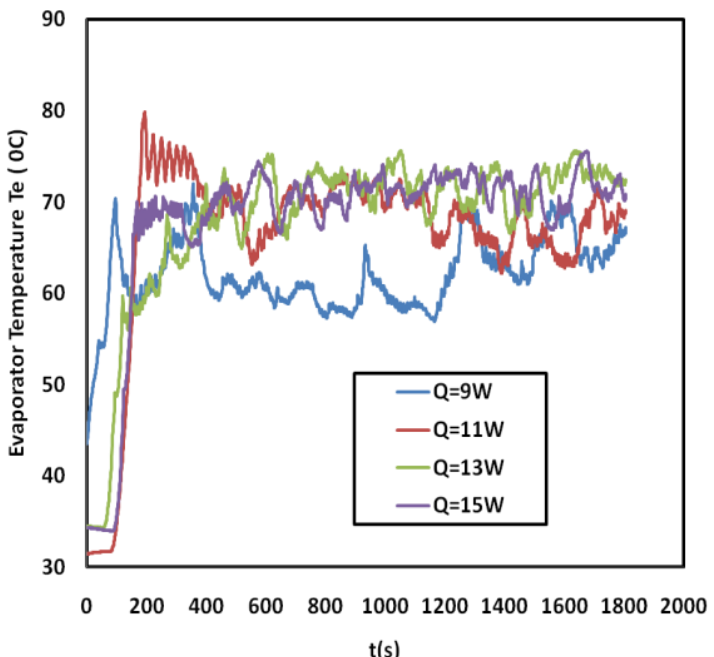

Fig. 2. Effect of heat input on evaporator temperature in horizontal orientation for Acetone at FR $=80 \%$

It is evident from the figure that there is a continuous pressure pulsation during the flow in a PHP. The evaporator temperature versus time curve is periodic in nature. It is also clear that the fluctuations in the evaporator temperature is more at lower heat input of 9 $\mathrm{W}$ due to intermittent motion of the working fluid and takes more time to reach the steady state.

Figure 3 shows the variation of condenser wall temperature with respect to time at different heat inputs in horizontal orientation for acetone at a fill ratio of $70 \%$. The variation of condenser temperature with respect to time is less at lower heat input of $9 \mathrm{~W}$ compared to higher heat input of $15 \mathrm{~W}$. This is because of very slow and intermittent motion of the working fluid at lower heat input. As the movement of the working fluid is slow at lower heat input due to lower energy levels, the hot fluid takes more time to reach the condenser section from the evaporator section. Thus the rise in the temperature of the cooling fluid is very less which results in lower variation of condenser temperature at lower heat load of $9 \mathrm{~W}$. But on the contrary, at a higher heat load of $15 \mathrm{~W}$, even though the movement of the fluid is slow initially due to the inertia of the system, the movement is picked up after $1200 \mathrm{~s}$ which results in the subsequent drop in the condenser temperature.

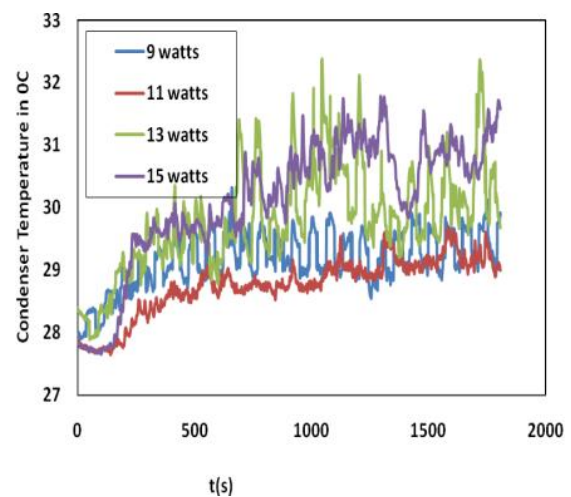

Fig. 3. Effect of heat input on condenser temperature in horizontal orientation for Acetone at FR $=70 \%$

Figure 4 shows the bar chart of temperature difference between evaporator and condenser at steady state in horizontal orientation for Acetone at different heat inputs at a fill ratio of $70 \%$. It is evident that the temperature difference between evaporator and condenser decreases with increase in heat input. As the movement of the fluid is very slow at lower heat input which is associated with lot of fluctuations, the temperature difference between evaporator and condenser is higher at lower heat input. Similar trends are observed when the PHP is tested in the vertical orientation. However, the results of horizontal orientation are reported in Fig.4.

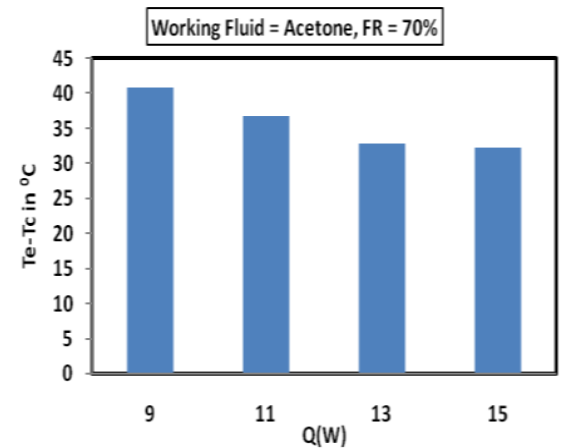

Fig. 4. Effect of heat input on temperature difference 
in horizontal orientation for Acetone at $\mathrm{FR}=70 \%$

\subsection{Effect of working fluid on temperature}

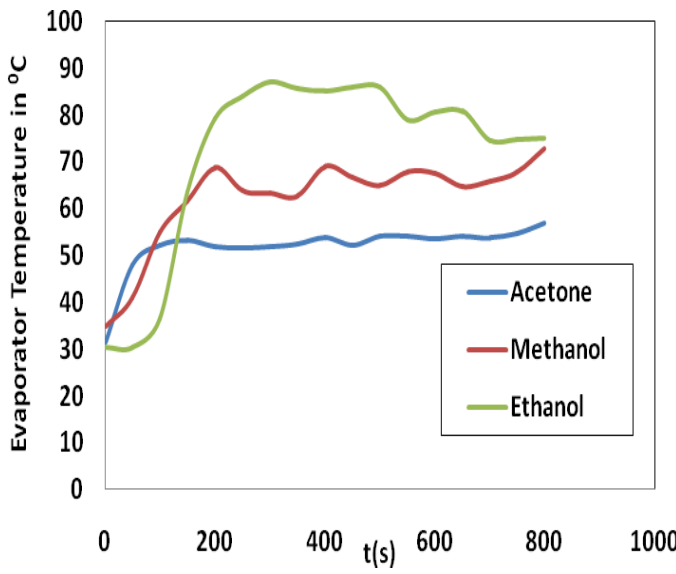

Fig. 5. Effect of working fluid on evaporator temperature in horizontal orientation at $\mathrm{Q}=13 \mathrm{~W}$ and $\mathrm{FR}=70 \%$

The variation of evaporator wall temperature with respect to time for different working fluids in the horizontal orientation at a fill ratio of $70 \%$ and at a heat input of $13 \mathrm{~W}$ is depicted in Fig. 5. It can be seen that the evaporator wall temperature at steady state is higher in case of Ethanol and lower in the case of Acetone due to higher saturation temperature for Ethanol. It is also observed that the system takes more time to reach the steady state in case of Ethanol compared to Acetone. More fluctuations are observed in evaporator wall temperature of Ethanol in view of its higher latent heat. During the course of the present study, the maximum evaporator temperatures measured for different working fluids ranges between $60^{\circ} \mathrm{C}$ and $80^{\circ} \mathrm{C}$. Table 1 shows the values of latent heat and specific heat at evaporator temperatures of $60^{\circ} \mathrm{C}$ and $80^{\circ} \mathrm{C}$ for Acetone, Methanol and Ethanol.

From Table 1, it is seen that Acetone has lower value of latent heat compared to Methanol and Ethanol at $60^{\circ} \mathrm{C}$ and $80^{\circ} \mathrm{C}$. A low latent heat will cause the liquid to evaporate more quickly at a given temperature and a higher vapor pressure; the liquid slug oscillating velocities will be increased and the heat transfer performance of the PHP will be improved.

From Table 1, it is also clear that Methanol and Ethanol have slightly higher value of specific heat compared to Acetone. A high specific heat will increase the amount of sensible heat transferred. Because the majority of the total heat transfer in a PHP is due to sensible heat, a fluid with a high specific heat is desirable. Hence, Acetone, Methanol and Ethanol are the preferred working fluids for the operation of PHP.

The variation of condenser wall temperature with time for different working fluids in the horizontal orientation at a fill ratio of $70 \%$ and at a heat input of $13 \mathrm{~W}$ is reported in Fig. 6. The fluctuations in the condenser wall temperature are much lower compared to the wall temperature of the evaporator (Fig. 5).

This is in view of single phase flow in the condenser and two phase flow in the evaporator. From the figure, it is also observed that the condenser wall temperature is lower for Ethanol and higher for Methanol and
Acetone. As there is an existence of less vapor while entering into the condenser in case of Ethanol, only a small amount of heat will be released due to latent heat. Thus Ethanol gets sub cooled to a greater extent. However, in case of Acetone and Methanol, the amount of vapor will be more when it enters the condenser and consequently the sub cooling effect will be much lower. This results in higher condenser wall temperature for Acetone and Methanol.

Similar results are obtained during the experimentation even in the vertical orientation of PHP.

Table 1 Properties of working Fluid

\begin{tabular}{|c|c|c|c|c|}
\hline & \multirow{2}{*}{$\begin{array}{c}\text { Evaporator } \\
\text { Temperature } \\
\left.{ }^{0} \mathrm{C}\right)\end{array}$} & \multirow{2}{*}{$\begin{array}{c}\text { Latent } \\
\text { Heat } \\
(\mathrm{kJ} / \mathrm{kg})\end{array}$} & \multicolumn{2}{|c|}{$\begin{array}{c}\text { Specific Heat } \\
(\mathrm{kJ} / \mathrm{kgK})\end{array}$} \\
\hline & & & Liquid & $\begin{array}{c}\text { Vap } \\
\text { or }\end{array}$ \\
\hline \multirow{2}{*}{ Acetone } & 60 & 517 & 2.29 & $\begin{array}{c}1.38 \\
6\end{array}$ \\
\hline & 80 & 495 & 2.39 & $\begin{array}{c}1.44 \\
4\end{array}$ \\
\hline \multirow[t]{2}{*}{ Methanol } & 60 & 1130.5 & - & 1.57 \\
\hline & 80 & 1084.4 & - & 1.7 \\
\hline \multirow[t]{2}{*}{ Ethanol } & 60 & 988.9 & 2.78 & 1.54 \\
\hline & 80 & 960 & 3.03 & 1.61 \\
\hline
\end{tabular}

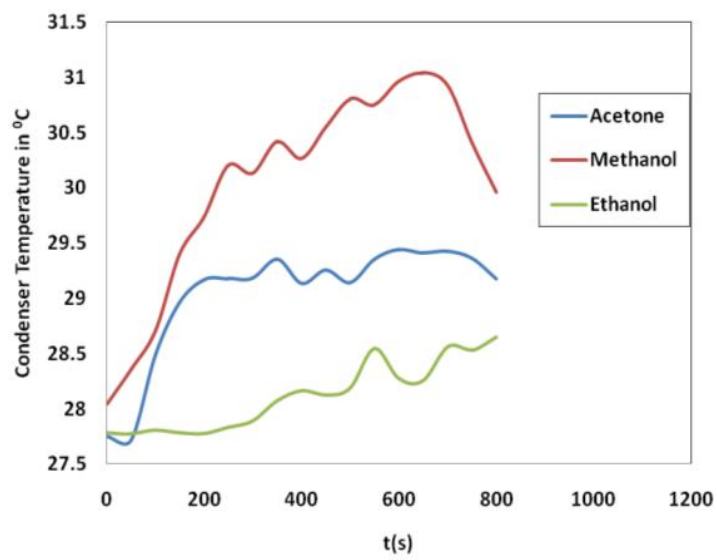

Fig. 6. Effect of working fluid on condenser temperature in horizontal orientation at $\mathrm{Q}=13 \mathrm{~W}$ and $\mathrm{FR}=70 \%$

\subsection{Effect of fill ratio on temperature}

It is reported in the literature (Khandekar, 2004) that the PHP works as a true pulsating device when the fill ratio is between $20 \%$ to $80 \%$. The exact range will differ for different working fluids, operating parameters and construction. More the bubbles (lower fill charges), more is the degree of freedom but simultaneously there is less liquid mass for sensible heat transfer. Fewer bubbles (higher fill charges) cause less perturbations and the bubble pumping action is reduced thereby lowering the performance. Thus an optimum fill charge exists and it is stated that $50 \%$ to $80 \%$ is the optimum fill ratio for a PHP. Considering this, the transient experiments are conducted during the course of the present work for different fill ratio ranging from $60 \%$ to $80 \%$.

The variation of evaporator wall temperature with respect to time for Acetone in horizontal orientation at a 
heat input of $13 \mathrm{~W}$ for different fill ratio is depicted in Fig. 7. From the figure it can be seen that the evaporator temperature is slightly higher at lower fill ratio of $60 \%$. As more vapor phase exists in the PHP at $60 \%$ fill ratio, less heat is being transferred from the wall to the fluid. This results in higher evaporator wall temperature at a fill ratio of $60 \%$.

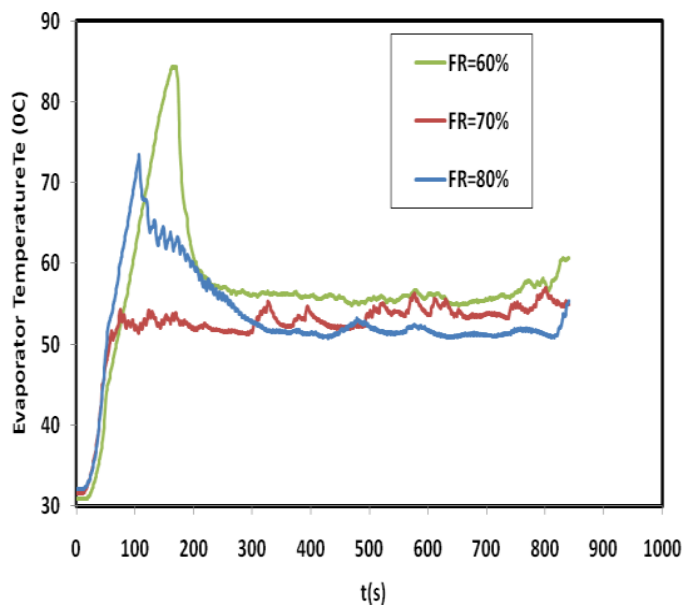

Fig. 7. Effect of fill ratio on evaporator temperature in horizontal orientation at $\mathrm{Q}=13 \mathrm{~W}$ for Acetone

Figure 8 shows the temperature difference between evaporator and condenser at steady state in horizontal orientation of PHP at different fill ratios for Acetone at a heat load of $13 \mathrm{~W}$. From the figure it is clear that the temperature difference between the evaporator and condenser is lower at a lower fill ratio of $60 \%$. At lower fill ratio, the saturation temperature is lower. The pressure difference between a liquid slug and a vapor bubble will decrease at lower fill ratio which will reduce the saturation temperature. As the pressure difference between a liquid slug and a vapor bubble decreases, the temperature difference also decreases. However, sufficient pumping action is created leading to more vapor phase in the tube with a consequent decrease in the heat transfer. Because of lower heat transfer from the wall to the fluid, the temperature difference between evaporator and condenser reduces.

\subsection{Effect of orientation on temperature}

Figure 9 shows the temperature difference between evaporator and condenser at steady state for Acetone, Methanol and Ethanol both in the horizontal and vertical orientations at a heat load of $15 \mathrm{~W}$ and at a fill ratio of $60 \%$. From the figure, it is clear that the temperature difference between evaporator and condenser is lower in the horizontal mode of operation of PHP for all working fluids considered.

As the fluid has to move against gravity in the vertical mode, there is no smooth movement of the working fluid which increases the temperature difference between evaporator and condenser.

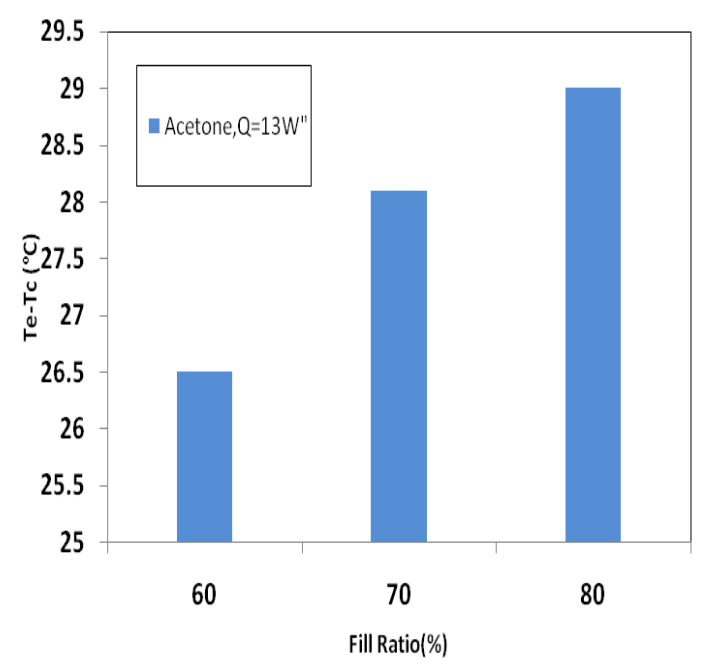

Fig. 8. Effect of fill ratio on Temperature difference in horizontal orientation for Acetone at $\mathrm{Q}=13 \mathrm{~W}$

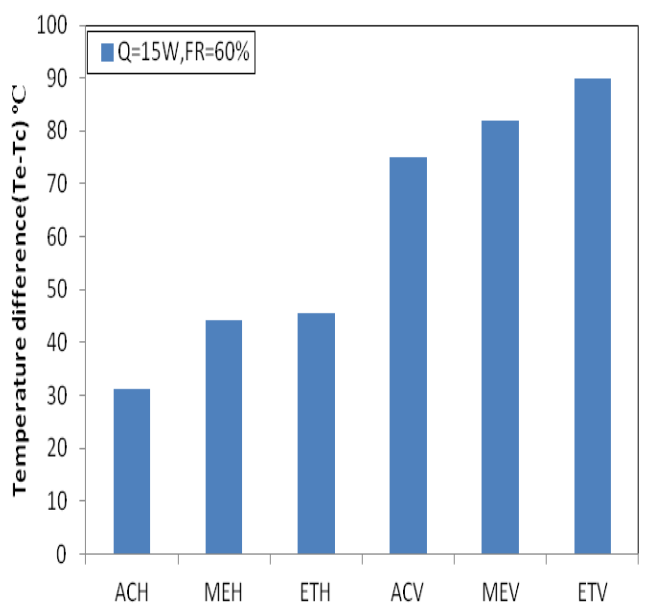

Fig. 9. Effect of orientation on Temperature difference for different fluids at $\mathrm{Q}=15 \mathrm{~W}$ and $\mathrm{FR}=60 \%$

\subsection{Variation of thermal resistance}

The Thermal Resistance of PHP is given by:

$R=\frac{T_{e}-T_{c}}{Q} \quad(\mathrm{~K} / \mathrm{W})$

Figure 10 shows the variation of thermal resistance with heat load for Acetone in the horizontal orientation for different fill ratios. From the figure it is clear that the thermal resistance decreases with increase in heat input at all fill ratios considered. The fill ratio of $60 \%$ exhibits the lower values of thermal resistance compared to higher fill ratio of $70 \%$ and $80 \%$. As the temperature difference between evaporator and condenser is less at lower heat load of $60 \%$ (Fig. 8), the magnitude of thermal resistance is also less. This shows that the heat transfer characteristics in a PHP are better at lower fill ratios. 


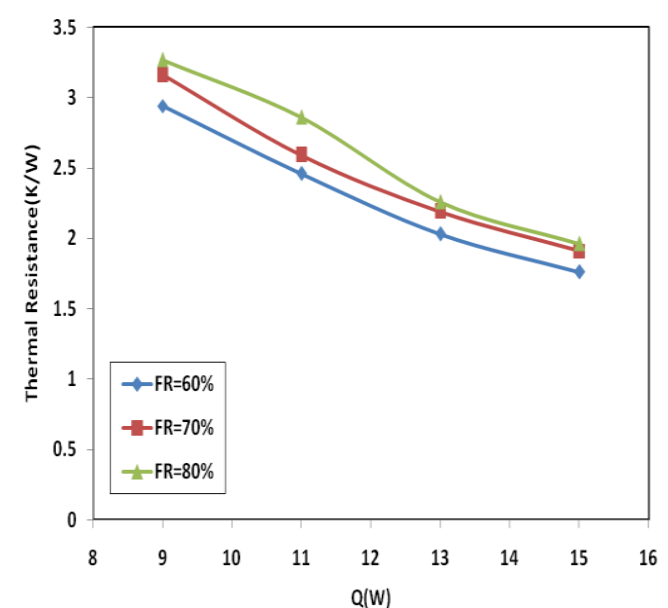

Fig. 10. Effect of fill ratio on Thermal Resistance in horizontal orientation for Acetone

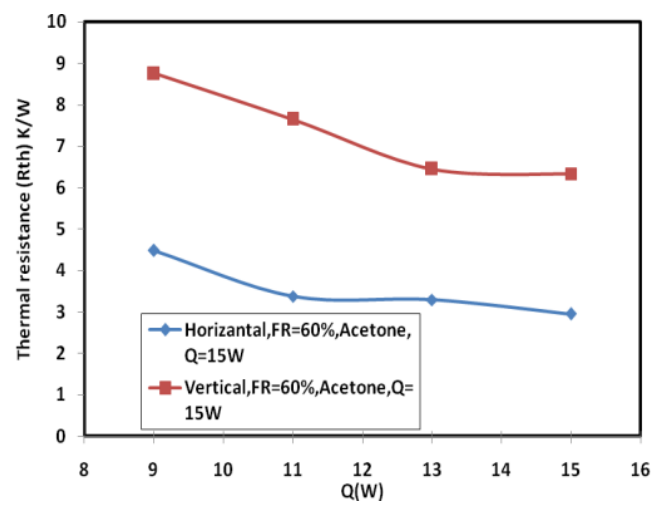

Fig. 11. Effect of orientation on Thermal Resistance for Acetone at $\mathrm{FR}=60 \%$

Figure 11 shows the variation of thermal resistance with heat load at steady state for Acetone both in the horizontal and vertical orientations and at a fill ratio of $60 \%$. It is observed that the thermal resistance decreases with increase in heat load both in the horizontal and vertical orientations. However, it is clear that the magnitude of thermal resistance is lower in the horizontal orientation of operation of PHP compared to vertical orientation which shows that the PHP operation in the single loop becomes more and more inefficient in the vertical orientation. As the temperature difference between evaporator and condenser is less in the horizontal orientation, the thermal resistance is also less. It is due to the fact that the fluid flow is smooth and simple in the horizontal orientation compared to vertical orientation. In the vertical orientation, the fluid flow is influenced by gravitational effects. Hence, the resistance for heat transfer and flow are more in vertical orientation.

Figure 12 shows the thermal resistance at steady state for Acetone, Methanol and Ethanol both in the horizontal and vertical orientations at a heat load of 13 $\mathrm{W}$ and at a fill ratio of $70 \%$. It is observed that the thermal resistance is lower in the horizontal orientation of operation of PHP for all working fluids considered. As the temperature difference between evaporator and condenser is less for all fluids considered in the horizontal orientation, the thermal resistance is also less. It also indicates that the heat transfer characteristics of single loop PHP are better in the horizontal orientation.

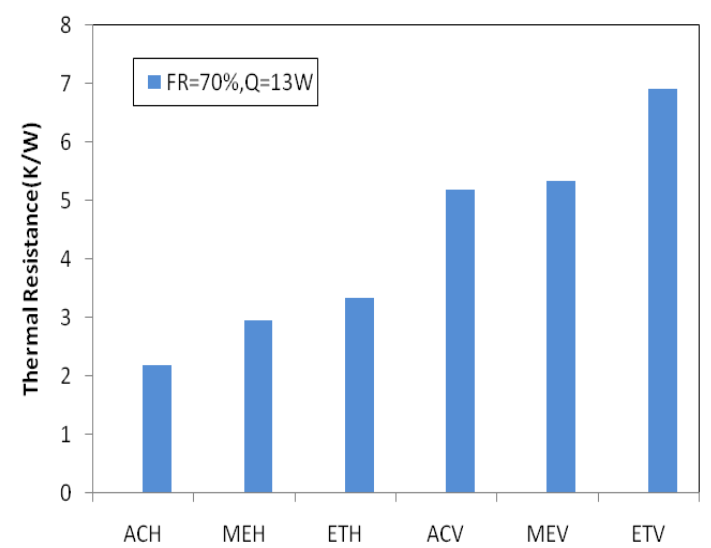

Fig. 12. Effect of orientation on Thermal Resistance for different fluids at $\mathrm{Q}=13 \mathrm{~W}$ and $\mathrm{FR}=70 \%$

\subsection{Variation of heat transfer coefficient}

The heat transfer coefficient of a PHP is given by (Faghri 1995):

$$
h=\frac{Q}{A_{s}\left(T_{e}-T_{c}\right)} \quad\left(\mathrm{W} / \mathrm{m}^{2} \mathrm{~K}\right)
$$

Figure 13 shows the variation of heat transfer coefficient with varying heat load for Acetone in the horizontal orientation at different fill ratios. From the figure, it is seen that the heat transfer coefficient increases with increase in heat load at all fill ratios. Higher values of heat transfer co-efficient can be seen at a lower fill ratio of $60 \%$ which indicates better performance of PHP.

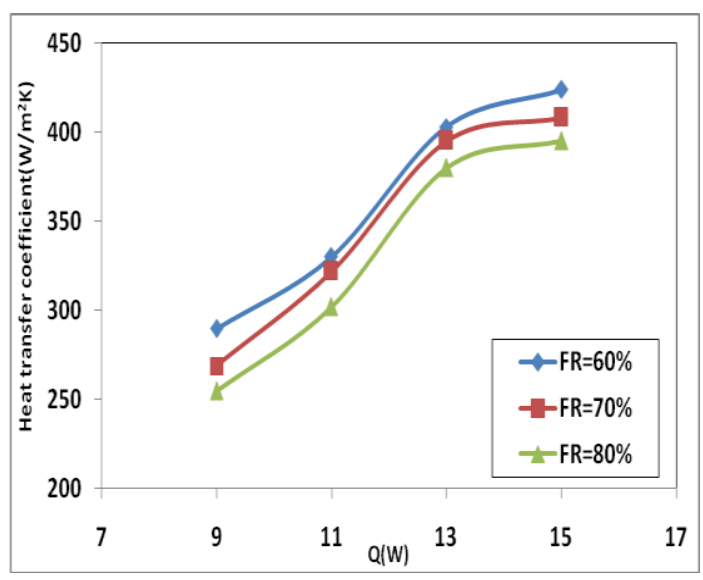

Fig. 13. Effect of fill ratio on Heat Transfer Coefficient in horizontal orientation for Acetone

Figure 14 shows the variation of heat transfer coefficient at steady state with respect to different heat loads for Acetone both in the horizontal and vertical orientations at a fill ratio of $60 \%$. Figure shows that the heat transfer coefficient increases with increase in heat load both in the horizontal and vertical orientations. It 
is observed that the heat transfer coefficient is higher in the horizontal orientation because of the fact that the temperature difference between evaporator and condenser is less in the horizontal orientation which results in the consequent increase of heat transfer coefficient.

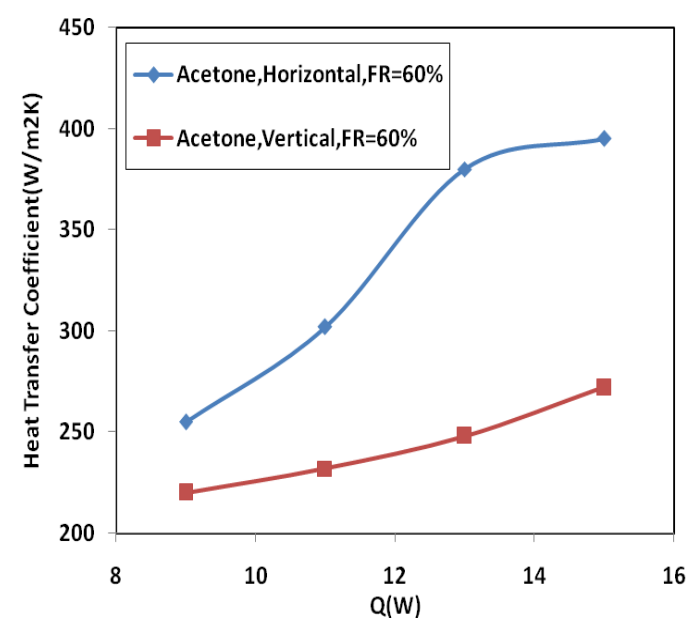

Fig14. Effect of orientation on Heat Transfer coefficient for Acetone at $\mathrm{FR}=60 \%$

\section{Conclusion}

In the present work, the experimental investigations are carried out on a single loop PHP. The effects of heat input, working fluid, fill ratio and orientation on the performance of PHP are studied.

Following conclusions are drawn from the present experimentation:

- The evaporator and condenser wall temperature variation with time is found to be periodic.

- The temperature difference between evaporator and condenser at steady state is found to be less for Acetone both in the horizontal and vertical orientations of operation of PHP compared to Ethanol and Methanol.

- Acetone is observed to be more suitable working fluid for PHP operation under different operating conditions.

- At a fill ratio of $60 \%$, the PHP is found to exhibit better heat transfer characteristics.

- The horizontal orientation of operation of single loop PHP is proved to be better in terms of lower thermal resistance and higher heat transfer coefficient.

\section{ACKNOWLEDGEMENTS}

The authors wish to thank AICTE and B M S College of Engineering for the research grant on Heat Pipes. The authors express their gratitude to the Undergraduate project team comprising Gadagi Amish Pratapa, A S Sochipem Zimik, Babu B and Kiran R for their valuable cooperation in the conduction of the experiments.

\section{REFERENCES}

Akachi, H. (1990). Structure of Heat Pipe. US patent, 4921041.

Faghri, A. (1995). Heat Pipe Science and Technology. Washington, USA, Taylor and Francis

Cai, Q., C. L. Chen, J. F. Asfia (2006). Operating Characteristic Investigations in Pulsating Heat Pipe. Journal of Heat Transfer 128(12), 13291334.

Charoensawan, P., S. Khandekar, M., Groll, and P. Terdtoon (2001). Closed loop pulsating heat pipes, part-A; Parametric experimental investigations. Applied Thermal Engineering 23(6), 2009-2020.

Khandekar, S., P. Charoensawan, M. Groll and P. Triton (2003). Closed Loop Pulsating Heat Pipes, Par-B: Visualization and Semi Empirical Modeling. Applied Thermal Engineering 23(16), 2021- 2033.

Khandekar, S. (2008, April). Multiple Quasi- Steady States in a Closed Loop Pulsating Heat Pipe. NTUS-IITK $2^{\text {nd }}$ joint workshop in mechanical, Aerospace and Industrial Engineering, IIT, Kanpur, India.

Khandekar, S. (2002). Pulsating Heat Pipe: ThermoFluidic Characteristic and Comparative Study with Single Phase. Thermosyphon Proceeding of $12^{\text {th }}$ International heat transfer conference, Grenoble, France 4, 459-464.

Khandekar, S. (2004). Thermo Hydrodynamics of Pulsating Heat Pipes. Ph. D Dissertation, University of Stuttgart, Germany.

Kline, S. J. and K. N. Mcclintock (1953). The Descriptions of Uncertainties in Single Sample Experiments. Mechanical Engineering 75.

Meena, P., S. Rittidech and P. Tammasaeng (2008). Effect of inner Diameter and Inclination Angles on Operation Limit of Closed-loop Oscillating Heat Pipes with Check Valves. American Journal of Applied Sciences 1(2), 100-103.

Rama Narasimha, K. (2009). Studies on Pulsating Heat Pipes. Ph. D Dissertation, Visveswaraya Technological University, India.

Rama Narasimha, K., M.S. Rajagopal and S. N. Sridhara (2012). Influence of Heat Input, Working Fluid and Evacuation Level on the Performance of a Pulsating Heat Pipe. Journal of Applied Fluid Mechanics 5(2-10).

Rama Narasimha, K., M.S. Rajagopal, S. N. Sridhara and K. N. Seetharamu (2010). Parametric studies on Pulsating Heat Pipes. International Journal for Numerical Methods for Heat and fluid Flow 20(4), 392-415. 
R. Naik et al. / JAFM, Vol. 6, No. 2, pp. 267-275, 2013.

Liu, S., J. LI, X. DONG and H. CHEN (2007). Experimental Study of Flow Pattern and Improved Configuration for Pulsating Heat Pipes. Journal of Thermal science 16(1), 56-62.
Yang, H., S. Khandekar and M. Groll (2008). Operational limit of closed loop pulsating heat pipe. Applied Thermal Engineering 128(1), 49-59. 